\title{
Impact of Playing Pokémon Go on Wellness
}

\author{
Shahrokh Nikou \\ Åbo Akademi University \\ snikou@abo.fi
}

\author{
Julian Tarvoll \\ Åbo Akademi University \\ jtarvoll@,abo.fi
}

\author{
Anssi Öörni \\ Åbo Akademi University \\ anssi.oorni@abo.fi
}

\begin{abstract}
The positive and negative effects of playing video games have been actively discussed for as long as the games have existed. Until recently, game playing has been accused of having mostly negative effects on one's wellbeing, especially on health. However, the tone of the discussion has recently started to change. For example, healthcare professionals have praised Pokémon Go game for its positive impact on physical activity. The research, though, has largely focused on small subsets of wellness dimensions. The aim of this study is to find out if playing Pokémon Go can positively affect the player's wellness. We propose a conceptual model to assess the link between playing Pokémon Go and the theorized dimensions of wellness utilizing a dataset containing 370 active players. Contrary to the widely held expectations, our analysis does not indicate significant relationship between playing Pokémon Go and some of the wellness dimensions, such as social or physical wellness. However, we find that playing Pokémon Go positively influences the player's overall wellness through the dimension of emotional wellness.
\end{abstract}

\section{Introduction}

The amount of time spent using different types of media has drastically increased throughout the most recent years. From 2005 to 2010, the amount of daily media use among young American people between the ages of 8 and 18 has increased from 6 hours and 21 minutes to 7 hours and 38 minutes [1]. The increase in media use is partly due to the technological advancements, which turned cell phones into media content delivery platforms [1]. From 2011 to 2017, the amount of young American people who owned a smartphone has increased from about 35 percent to 77 percent [10]. With this increase, the time spent, on average, per day playing video games increased from 49 minutes to 1 hour and 13 minutes. Much of this increase comes from the use of cell phones as a way of playing video games [1]. A closely related topic to playing video games is whether the effects of playing are positive or negative. Using a search engine to perform two separate searches, one for video games and health benefits, and one for video games and health risks, quickly reveals twice as many search results for the latter. Whether a video game has the ability to affect someone in a positive or negative way can largely be reliant on the genre and content of the game. With the steadily increasing amount of time spent playing video games, even from early ages, it is more important now than ever to be aware of how it affects people. During the summer of 2016, Niantic launched a mobile game called Pokémon Go. The game was well received and achieved more than 650 million downloads worldwide and it quickly became a global phenomenon [2]. The Pokémon world connects with augmented reality to the real world, and players are required to physically move about to play the game. Healthcare professionals have praised the game for encouraging physical activity and potentially increasing life expectancy, if long-term engagement can be sustained [3]. Arguably, most people play the game for the sake of playing itself; however, with hundreds of millions of people walking, running, and cycling around, one could almost call Pokémon Go the most successful fitness application in terms of changing behavior of its users for the better through gamification. While some early reports indicate that Pokémon Go has had positive effect on wellness, little detailed research is available on the game's impact on different wellness dimensions. The aim of this research is to examine if and how playing Pokémon Go influences the players' wellness. Because wellness is a multidimensional construct, it is possible that only certain dimensions are affected. Thus, our main research question is: Does playing Pokémon Go influence the players' wellness, and which wellness dimensions are most affected?

\section{Theoretical background}

The aim of this section is to review the relevant literature on Wellness and Pokémon Go to establish a foundation from which we develop the conceptual model and the research hypotheses. We start with an 
introduction of the wellness concept and then review its constituent dimensions. Finally, we discuss the Pokémon Go game, to gain better understanding of how the game can affect wellness.

\subsection{Definition of Wellness}

Wellness is a modern term, with ancient roots, that is often used interchangeably or alongside with other words such as health, wellbeing, healthy living, quality of life, medicine, and fitness. [4]. Literature identifies multiple dimensions of wellness, all dimensions equally important in order to reach what Dunn [6] describes as high-level wellness. Wellness, although extensively used in modern times, does not have a single, generally agreed on definition, and wellness researchers have to choose between several alternatives. In this research, we follow Corbin and Pangrazi's [4-5] definition of wellness: "wellness is a multidimensional state of being describing the existence of positive health in an individual as exemplified by quality of life and a sense of wellbeing". In their definition for wellness, Corbin and Pangrazi [4, p. 3] state that the positive health in an individual is exemplified by quality of life and a sense of wellbeing. In other words, they use quality of life and wellbeing as indicators for wellness. Using wellbeing as an indicator for wellness is fitting considering, for example, that social psychology studies indicate that social wellbeing is the absence of negative feelings and conditions resulting from depression, distress, anxiety or substance abuse [7]. In short, the adopted wellness definition highlights several important, unique characteristics of wellness.

\subsection{The Wellness dimensions}

While there is a consensus on that wellness is a multidimensional concept, the number of proposed wellness dimensions varies from one account to another [4-5]. Hettler [8] developed one of the most widely known models, "The Six Dimensions of Wellness Model", which identifies occupational, physical, social, intellectual, spiritual, and emotional dimensions of wellness and describes how they contribute towards healthy living. The main purpose of the model is to serve as a holistic framework for identifying and describing the wellness dimensions [9, p. 354]. The model will be used in this research, yet we exclude the occupational wellness dimension from further discussion as we do not consider it relevant to study of the effects of personal activity, such as game playing, on one's wellness. We next discuss the other dimensions of the model in more detail.
The physical dimension of wellness comprises three important factors to physical development. First, a healthy diet and nutrition is known to have positive impact on a person's physical development, while use of drugs and smoking as well as consuming excessive amounts of alcohol affects physical development negatively [8]. Second, an equally important aspect of physical development is exercise. The recommendation is for a variety of exercises performed over longer periods of time. Monotonous exercise is discouraged mainly because the physical aspects of the human body need to develop as a whole. Therefore, one needs to create a balance between physical strength, endurance and flexibility. Exercise of varied type should be performed with the correct technique and in moderation according to the person's physical condition, in order to reduce the risk for injuries and exhaustion. The American College Sports Medicine and the American Heart Association recommend at least 30 minutes of moderate-intensity aerobic (endurance) activity five days a week or vigorousintensity activity for 20 minutes three days a week for healthy adults aged 18-65 years as a way to promote and maintain health [11]. The third component of the physical wellness dimension relates to the signs emitted by the human body and how one chooses to respond to them. Such signs indicate how the body feels and range from minor signs like exhaustion, for which rest can be used as treatment, to signs indicating illnesses requiring professional help and medication as the proper response [8].

The social dimension refers to a range of behaviors from a person's way of interacting with others to how she participates in communities. To what level a person is able to take part in a community is largely determined by her social skills. Keyes [12] identifies three challenges regarding the social dimension of wellness: social integration, social acceptance, and social contribution. Social integration is about the quality of one's relationship with the society and community. In the optimal scenario, social wellbeing is present in the form of a feeling that the individual has something in common with the others in the community or society. On the other side, if the community or society does not reflect the same values or the same lifestyle, the outcome may be one of estrangement and social isolation. The second challenge is social acceptance. In short, social acceptance has to do with whether or not a person will be included in or excluded from communities, relationships and groups. Social acceptance and rejection is something everyone will experience through their life. According to Keyes [12, p. 122], social acceptance of others shows a great amount of 
trust and belief in others being diligent and hardworking. Social rejection, in turn, may have emotional, cognitive, behavioral, and biological outcomes such as hurt feelings, anxiety, anger, sadness, depression, jealousy, and reduced self-esteem [13, pp. 256-258]. Finally, social contribution is an evaluation of how valuable a certain person is to the society or community [12]. Becoming valuable to a community can be achieved through participating in different kinds of activities, or taking certain roles within the community. When it comes to taking part in society, Hettler [8, p. 2] suggest that it is optimal to contribute to communities and live in harmony with others.

The intellectual wellness relates to cognitive skills and abilities. The cognitive abilities can be seen as brain functions needed to perform tasks typically revolving around how a person learns, remembers, pays attention and solves problems [14, p 2006]. When it comes to intellectual development, Hettler [8, pp. 2$3]$ suggests that one should always seek to challenge these abilities with intellectual and creative activities, to expand knowledge and train skills. Stimulation of intellectual health is beneficial for people in every age. Improving and maintaining cognitive functions is recommended for countering what is known as normal age related cognitive decline. Cognitive decline is a process that is somewhat unavoidable, resulting in gradually worse cognitive abilities and possibly ending in Alzheimer's disease or other conditions, which fall under the label of dementia [15]. Cognitive decline can be countered, to a degree, with mentally stimulating activities. Hettler [8] emphasizes the importance of development also within the intellectual dimension of wellness and argues that mentally stimulating activities can also be used as tools to promote intellectual growth and development of the human mind. Mentally stimulating activities, also known as cognitive activities, challenge one functional part or several functional parts of the brain. Classical examples of cognitive activities include reading books, solving crossword puzzles, playing musical instruments, and playing board games or card games. Some cognitive activities, like doing crossword puzzles focus on memory, more specific long-term memory, while others, like playing an instrument exercises motor functions. Some cognitive activities, however, have broader influence on intellectual wellness in the sense that they stimulate multiple cognitive functions. Board games and card games, for example, can affect not only short-term memory but also strategic thinking.

Dunn [6] was one of the first scholars to introduce the spiritual dimension of wellness when he reasoned that an individual could hardly ever be physically well if she did not feel spiritually well [6, p. 789]. Spiritual dimension of wellness concerns striving to involve beliefs and values that provide purpose in life [8]. While spirituality is very often defined in terms of religiosity, the concepts are distinguishable. Spirituality, as a concept, is much broader and embraces beliefs and values, whereas religiosity is narrower and typically refers to behaviors [16]. Religiosity is in general considered public, often exhibited through the use of religious institutions, whereas spirituality is more of a private matter not necessarily expressed publicly [17].

The individuals' feelings are central to the emotional wellness dimension. Hettler [8, p. 2] argues that emotional wellness is achieved through feeling positive and enthusiastic about oneself and one's life. The ability to feel positive and enthusiastic is to a huge degree dependent on one's self-esteem [18, p. 833]. An interesting discovery made by Abood and Conway [19] confirm that people with high self-esteem have a greater tendency to engage in health-enhancing behaviors. Correspondingly, participating in healthenhancing behaviors could also lead to an enhanced perception of self-worth. Wellness programs typically revolve around health-enhancing behaviors within every dimension of wellness. The discovery of Abood and Conway [19] shows why the emotional wellness dimension is considered as one of the major wellness dimensions, as emotional wellness is a decisive factor in the individual's willingness to change her behavior in a way that promotes positive health within other dimensions of wellness.

\subsection{Pokémon to Pokémon Go}

Satoshi Tajiri from a western suburb in Tokyo enjoyed most of his days as a child collecting insects. Tajiri was fascinated by the different insects and strived to catch as many unique insects as possible. With urbanization, finding good places to catch insects became a challenge. The idea of turning his childhood hobby of collecting insects into a game for others to play emerged when he first encountered the Game Boy console [20]. In 1998, Tajiri created the Pokémon franchise which is managed by The Pokémon Company, consisting of three businesses owning the copyright in Pokémon: Nintendo, GAME FREAK and Creatures [21]. In what started as video games for the Game Boy, Tajiri introduced its audience to the first generation of 151 Pokémon. The word Pokémon comes from the Romanized contraction of the Japanese words Poketto Monsutā, which simply translate into "pocket monsters". The first Pokémon games released for the Game Boy let the player starts a journey as a 
so-called Pokémon trainer, catching and training Pokémon, and battling other Pokémon trainers. The Pokémon franchise became a huge success as it was developed for other media. Some 280 million units of Pokémon video games have been sold worldwide, 21.5 billion cards shipped worldwide, animated TV shows aired in 95 countries and regions, and 18 movies released with Box-office revenue of 675 million U.S. dollars [21]. The market of the franchise was estimated to be 42.2 billion U.S. dollars by the end of 2016 , making it one of the biggest cross-media franchises.

The American software company Niantic, which specializes in developing augmented reality mobile games, released Pokémon Go in early July 2016. Pokémon Go was the second augmented reality game developed and released by the company. According to John Hanke [22], the founder of Niantic, the idea for Pokémon Go resulted from the April fool's joke by Google and The Pokémon Company, in which Pokémons spontaneously showed up in Google Maps. After pitching the idea of using mobile phones to catch Pokémon to The Pokémon Company, the idea became reality.

Pokémon Go took the Pokémon franchise to a whole new level by making it possible for users to act as Pokémon trainers in their everyday life. The application was launched and made available for both Android and iOS users all over the world on April 6, 2016. By using the built-in GPS function and the whole world as the game map, players could search far and wide for unique Pokémons [23]. Pokémon Go allows anyone who downloads the application to become Pokémon trainer and catch Pokémons all over the world. With the GPS function enabled on the mobile device, one's Pokémon trainer avatar takes the spot of the current location and moves around the map in the same way the player moves about in the real world. After the introduction of the game new players will get to choose a starter Pokémon just like the main protagonist Ash Ketchum does in the animated series [24]. With the starter Pokémon chosen, players can start to discover the world and start their quest to "Catch 'Em All" which is the slogan of the franchise.

\subsection{Finding Pokémon}

The first step for trainers to successfully catch Pokémon is to locate them. By using the built-in tracker of the application, trainers can get some help, as the Pokémon close to certain landmarks are displayed with a picture. Finding Pokémon requires trainers to actively move about to search for them. How Niantic determines, where and when a Pokémon spawns, appears to be a mystery. However geographic map markers appear to be used to make certain that certain types of Pokémon spawn close to their natural habitats [22], for example water type Pokémon spawning close to rivers and grass type Pokémon in parks. The frequency of spawning seems to be timed by intervals decided by Niantic and cellular traffic influences the density of spawning.

2.4.1. Progress in the game. Pokémon Go is a game that requires its players to gather experience points to progress. Once enough experience points have been earned the player will go up a level. Leveling up is fast in the beginning, but becomes gradually slower as the experience points needed to reach the next level increases for each consecutive level. When leveling up players can be rewarded with items that are otherwise only obtainable through the in-game shop for real money. Leveling up also allows the trainers to power up their Pokémon, increasing their offensive and defensive attributes, but leveling up also increases the level of the Pokémon that can be encountered when hunting.

2.4.2. Pokémon gyms. Once level five is reached Pokémon trainers are allowed to test their strength at the Pokémon gym. Before attempting to conquer a gym, trainers need to choose their team. The Pokémon gym is a prestigious arena that the teams fight to control. In order to conquer a Pokémon gym, one or more players of another team need to use their own Pokémon to fight the controlling team's Pokémon until there is none left and the new team can claim the gym. The gym battle requires strategizing in terms of deciding the best Pokémon to send to battle, but also quick reactions to dodge attacks of the opponent's Pokémon. Claiming the gym allows one person to leave a Pokémon there to defend it, and the controlling team can train the gym further by fighting the defending Pokémon. Leveling up the gym allows more team members to station a Pokémon there to defend it. This game design arguably encourages cooperation between players belonging to the same team to maximize their chances of getting rewards. Controlling a gym allow each player with a Pokémon in the gym to claim 10 Pokécoins roughly every 21 hours for up to 10 unique Pokémon gyms [25].

2.4.3. Pokémon Go and Wellness. The game is designed, for the most part, in a way that rewards physical activity. People who play the game actively will most likely spend more time outside, reducing exposure to indoor air pollutants and increasing the benefits of fresh air and sunlight. For instance, Kogan et al. [46] have recently found that playing the Pokémon Go helps players to reduce their anxiety 
about leaving the house, interacting with stranger and visiting new places and concluded that it could be a new opportunity to enhance both mental and physical health. In terms of social wellness, gym battles favor cooperation and lure modules attract other players, both enabling players with shared values to interact and build relationships. Yang and Liu [45] in their study of motives for playing Pokémon Go have found playing the game helps player to maintain their existing friendship and contributes to a better state of wellness. Benefits for the intellectual wellness dimension can come through strategizing and use of reaction skills at gym battles, but also from the use of motor skills when catching Pokémon. In terms of spiritual wellness, the game can be seen as intrinsically valuable as it may induce pleasure and happiness. Some may even find it meaningful to play. Emotional wellness benefits of playing Pokémon Go may follow the positive emotions and sense of achievement caused by playing while the physical benefits of playing may heighten one's self-esteem.

\section{Conceptual framework and hypothesis}

The National Human Activity Pattern Survey, among many other studies, has confirmed that people spend as much as 86 percent of their time indoors [26]. Spending excessive amounts of time indoors arguably has a negative impact on a person's physical wellness due to the exposure to indoor air pollution and being relatively stationary. The Pokémon Go game is developed in a way that incentivizes the player to go out and move about in search for Pokémon reducing the exposure to indoor pollutants and increasing exposure to sunlight, which reduces the risk of vitamin D deficiency and disruptions to one's life rhythms [2728]. Pokémon Go, as confirmed by their slogan "Get up and Go" was developed with the intention of getting people off the couch and becoming more active [29]. Niantic designed the game in a way that requires people to move about to gather and refill the game resources. Players are incentivized to move even more by allowing them to hatch Pokémon from eggs by moving about and by getting candy, needed for growing Pokémon, from walking with a Buddy Pokémon. Behavioral change is expected as the game rewards players based on their physical activity, most likely resulting in increased physical activity levels, but also increased fitness as the game serves a great source of motivation for various forms of exercise. Thus, we hypothesize:

H1: Playing Pokémon Go has a positive effect on the player's physical wellness.
Social wellness revolves around being able to live in harmony with others and contribute to communities [8], which calls for social integration. According to Keyes [12], social integration works best when people feel that they have something in common with the others, for example shared values. Through playing Pokémon Go the players in the same geographical areas are most likely to run into each other as the Pokémon spawn at the same locations for every player. This gives the players a common ground to interact and build relationships. Social interaction is also rewarded within the game, as players can form teams and the players in a team are able to cooperate, which makes it easier for them to conquer Pokémon gyms. With so many people, playing the game and sharing the same interests and goals, small local communities as well as online communities will emerge allowing the players to find their sense of belonging. Pokémon Go can be expected to form a framework for social integration and may have a positive effect on the player's social wellness. Thus, we hypothesize:

H2: Playing Pokémon Go has a positive effect on the player's social wellness.

When Hettler [8] advocated the intellectual wellness dimension, he emphasized the importance of intellectual development through challenging cognitive abilities. Challenging one's cognitive abilities and training of the intellectual skills were found important for intellectual wellness, for it slows down the inevitable cognitive decline and promotes intellectual growth. Through the assessment of the different aspect of the Pokémon Go game, it was discovered that the Pokémon Go players train their motor skills when catching Pokémon and fighting in gym battles. It was also discovered that the players fighting at gyms make strategic decisions, which could be decisive for the outcome of the gym battle. Another mentally challenging part of the game, which could influence the intellectual stimulation, is memorization of the Pokémon movements' patterns during the phase where the player attempts to catch it, to reduce the risk of the Pokémon dodging the catching device, Pokéball. Additionally, during gym battles players may dodge the special abilities of the incoming Pokémon if their reaction time is good enough and thus, gain an advantage over the opponents. As the Pokémon Go game has a range of implemented game mechanics, we posit that they may be used to train different intellectual functions which can be used for mental stimulation. Therefore, we expect that the players will experience increased intellectual wellness. Thus, we hypothesize:

H3: Playing Pokémon Go has a positive effect on the player's intellectual wellness. 
Through the assessment of the spiritual wellness dimension, Hettler [8] demonstrated the importance of pursuing beliefs and values that are meaningful to the individual. Such beliefs and values are collectively known as intrinsic values [30]. The source of intrinsic value may vary from person to person yet those items and events that induce pleasure and happiness are the most likely sources [31]. Because playing Pokémon Go may be of intrinsic value to the players by increasing the happiness and pleasure, it may increase the spiritual wellness of the players. Further work by Westgate [30] indicates that another important aspect of spiritual wellness is finding meaning and purpose in life. Because playing Pokémon Go may be meaningful and serve a purpose for those who play it, it may also increase the spiritual wellness of its players. Thus:

H4: Playing Pokémon Go has a positive effect on the player's spiritual wellness.

Feeling positive about oneself and one's life is essential to emotional wellness [8]. Jones and Frazier [18] pointed out that the ability to feel positive about oneself depends, to a large degree, on the person's selfesteem. Leary [32, p. 34] states self-esteem is closely connected to how well a person is valued and accepted by the others. Previously it was mentioned that Pokémon Go players are likely to find their belonging in the communities that emerge inside and around the game. As a result of feeling accepted in their social surroundings due to the shared values and goals, Pokémon Go players may notice an increase in their self-esteem. Additionally, increased emotional wellness may result from achievements in and having fun with the game. The game can also function as a way of relieving stress and countering emotional problems. Thus:

H5: Playing Pokémon Go has a positive effect on the player's emotional wellness.

While the theory identifies the most important dimensions of wellness there is no way of telling, apart from empirical testing, the relative strength with which each dimension influences one's overall wellness in the current setting. It has been documented that wellness perceptions do change, for example, as a factor of age [43]. From our perspective, this means that we have to test the influence of each individual wellness dimension on overall wellness, for only those influences of playing Pokémon Go on individual wellness dimensions that are also reflected in a comparable change in one's overall wellness should be considered meaningful. To test for the relevance of each individual wellness dimension on overall wellness, we formulate the following additional research hypotheses:
H6: The player's physical wellness is related to her overall wellness.

H7: The player's social wellness is related to her overall wellness.

H8: The player's intellectual wellness is related to her overall wellness.

H9: The player's spiritual wellness is related to her overall wellness.

H10: The player's emotional wellness is related to her overall wellness.

\section{Research methodology}

\subsection{Survey instrument}

An online questionnaire was developed as an instrument for collecting the data. For this study, the key independent variable is the amount of playing Pokémon Go. To ensure the most reliable data for this variable, it was decided to use one of the metrics tracked by the game itself. Out of the metrics tracked by the game, the amount of Pokémon caught and distance walked while playing Pokémon Go could be used. However, as discussed previously, Pokémon spawn with a higher density in urban areas due to the nature of the game design would not truly represent the amount played. As many aspects of the game revolved around walking, using the tracked distance to measure amount played seems to be an appropriate metric for amount of playing. Hence, we asked our respondents to report the distance walked while playing Pokémon Go as tracked by the game.

We developed 10 statement-like questions to measure the five identified wellness dimensions, two questions per each dimension. We asked respondents to rate on a seven-point Likert scale to which extent they agree or disagree with the statements. Before the actual data collection phase, the questionnaire was pilot tested among 26 active Pokémon Go players. Wording of some of the questions was adjusted due to issues raised by pilot testing. For overall wellness, we asked the respondents to rate the following statements: (i) rate your level of wellness before you started to play Pokémon Go" (ii) "rate your current level of wellness. For the dimension of physical wellness, we asked respondents to rate the following statements: (i) your level of physical wellness before you started to play Pokémon Go (ii) your current level of physical wellness. For the social wellness dimension, the respondents were asked to rate the following statements: (i) your level of social wellness before you started to play Pokémon Go (ii) your current level of social wellness. For the intellectual wellness dimension, we asked the respondents to rate the following statements: (i) your level of intellectual wellness before you started to play Pokémon Go (ii) your current level of intellectual wellness. For the 
spiritual wellness dimension, we asked the respondents to rate the following statements: (i) your level of spiritual wellness before you started to play Pokémon Go (ii) your current level of spiritual wellness. For the emotional wellness construct, we asked the respondents to rate the following statements: (i) your level of emotional wellness before you started to play Pokémon Go (ii) your current level of emotional wellness. The entire list of questions was asked to be rated, with $(-3)$ very low and $(+3)$ very high as the anchors.

By subtracting the past wellness levels from the current wellness levels, the change in wellness levels for every specific dimension could be obtained. The deltas were used to measure the change in one's overall wellness and each wellness dimension.

\subsection{Sample selection}

It was determined that the active Pokémon Go players within the Pokémon Go community on the social media site Reddit forms an appropriate sampling frame for our study, as its members come from all over the world, even though not all locations are equally represented. With the Pokémon Go subreddit consisting of over 670.000 subscribers, it was found infeasible to survey all of them due to the spam prevention procedures implemented by Reddit, which made contacting multiple users at once impossible. To create the most representative and unbiased sample of the Pokémon Go community on Reddit, it was necessary to make sure all possible respondents, regardless of their geographical location, have the same opportunity to participate in the survey. To ensure that the sample was as unbiased as possible the authors wrote down the usernames of all users who had created threads, or commented at the Pokémon Go subreddit during a 24-hour time span from 9th to 10th of March 2017. By using this method, all active users had the same opportunity to be picked for the survey, regardless of what time of the day they were active on. The number of active users registered by the authors within the time period was 2064. Because this number was relatively large and it would have been too time consuming to send a personal message to all of them, the authors randomly selected 50 percent of the group (1032 subscribers) to receive the survey. The sampled users received the survey in the form of a personal message to their Reddit account, and were encouraged to complete the questionnaire for the purpose of the research project. We also provided a general description in the beginning of the questionnaire about the purpose of the study and a short definition for each wellness dimensions. Reddit users who had received the survey, but for some reason were not active Pokémon Go players were encouraged to notify the authors, and refrain from taking the survey. After screening the data for unengaged responses and outliers, we obtained 370 valid and usable responses. Three responses were excluded from the sample because the standard deviation in each case were equal to zero, meaning that the respondents had answered the same on every statement and therefore most likely not been engaged in the survey. Additionally, 16 cases with a standard deviation less than 0.5 were manually investigated and removed due to similar concerns.

\subsection{Respondents' Profile}

The average age of the respondents is 27 years. Of the 370 respondents, 14.3 percent were female and 85.7 percent were male. These numbers differed drastically compared to the published demographic data for Pokémon Go players as in the late July 2016 the majority of Pokémon Go players (63 percent) were female. By September the same year the share of female players, however, had dropped to 53 percent [40]. Thus, some demographic deviations from the published statistics of Pokémon Go players exists in our data yet it is difficult to estimate the influence of these deviations as the demographics of active players seems to be in flux.

\section{Analysis and findings}

To perform the analysis, we obtained path analysis which is a special case of structural equation modeling [39]. In path analysis, the assumption is that all the variables are measured without error. Moreover, path analysis only contains observed variables and linear relationships. This choice was made due to the metric, distance walked, used to measure the amount of playing Pokémon Go.

\subsection{Path model results}

The collected data was analyzed making use of SmartPLS v.3 software to assess the hypotheses and also to examine the adequacy of the proposed research model. The $\mathrm{R}^{2}$ measures the explained variance of a dependent variable relative to its total variance and indicates the percentage of the combined predicting power of independent variables [34]. In this study, the $\mathrm{R}^{2}$ for the dependent variable, i.e., overall wellness is 33 percent.

The impact of playing Pokémon Go on physical wellness

Pokémon Go game design is based on people moving about in hunt of the Pokémon characters. We hypothesized (H1) that playing Pokémon Go has a positive effect on the player's physical wellness. 
Table 1. Path analysis

\begin{tabular}{|l|c|c|c|c|}
\hline & Mean & STDEV & $\begin{array}{l}t \text { - } \\
\text { statistics }\end{array}$ & $\begin{array}{l}p \\
\text { values }\end{array}$ \\
\hline $\begin{array}{l}\text { Emotional -> } \\
\text { Overall Wellness }\end{array}$ & 0.432 & 0.062 & 6.951 & 0.000 \\
\hline $\begin{array}{l}\text { Intellectual -> } \\
\text { Overall Wellness }\end{array}$ & 0.058 & 0.061 & 0.938 & 0.348 \\
\hline $\begin{array}{l}\text { Social -> Overall } \\
\text { Wellness }\end{array}$ & 0.114 & 0.056 & 2.052 & 0.040 \\
\hline $\begin{array}{l}\text { Spiritual -> Overall } \\
\text { Wellness }\end{array}$ & 0.035 & 0.053 & 0.590 & 0.555 \\
\hline $\begin{array}{l}\text { Physical -> Overall } \\
\text { Wellness }\end{array}$ & 0.319 & 0.048 & 6.619 & 0.000 \\
\hline Distance -> Social & 0.038 & 0.052 & 0.714 & 0.475 \\
\hline $\begin{array}{l}\text { Distance -> } \\
\text { Intellectual }\end{array}$ & 0.113 & 0.051 & 2.267 & 0.023 \\
\hline Distance -> Physical & -0.013 & 0.051 & 0.239 & 0.811 \\
\hline $\begin{array}{l}\text { Distance -> } \\
\text { Emotional }\end{array}$ & 0.094 & 0.043 & 2.214 & 0.027 \\
\hline Distance -> Spiritual & 0.129 & 0.032 & 4.032 & 0.000 \\
\hline
\end{tabular}

However, in the path analysis the path from distance walked to physical wellness is not statistically significant and, hence the model does not support hypothesis H1. Relatedly, in hypothesis H6, we stated that the player's physical wellness is related to her overall wellness. The path from physical wellness to overall wellness is statistically significant $(\beta=0.297, t$ $=6.62 \mathrm{p}<.000)$ in the model, which supports H6. This suggests that physical wellness is a relevant wellness dimension to our sample. We interpret our findings as follows: physical wellness related results indicate that playing Pokémon Go may have replaced other physical activity rather than increased the total amount of exercise, which is why playing the game does not seem to improve one's physical wellness. This finding contradicts with previous results. For instance, Kogan et al. [44] found that playing Pokémon Go positively impacts and enhances physical health. Moreover, several recent publications find that playing the game has enhanced physical activity of the PG players [4546].

The impact of playing Pokémon Go on social wellness

Pokémon Go game design includes a strong social component as the game rewards co-operation between its players. Hence, we hypothesized that playing Pokémon Go would positively impact social wellness (H2). However, the path between game playing and social wellness is not statistically significant (no support for H2). Relatedly, in H7, we stated that the player's social wellness is related to her overall wellness. The path from the social wellness to the overall wellness is statistically significant $(\beta=0.114, t$ $=2.05 \mathrm{p} \mathrm{<.05)} \mathrm{suggesting} \mathrm{that} \mathrm{social} \mathrm{wellness} \mathrm{is} \mathrm{a}$ meaningful dimension of wellness in our sample (H7 supported). Together, these findings suggest that people play Pokémon Go with existing friends rather than forming significant numbers of new relationships. This is consistent with a recent study, which finds that playing the game has increased the social interactions among players [47].

The impact of playing Pokémon Go on intellectual wellness

Some phases of playing Pokémon Go calls for strategizing, which led us to hypothesize, that playing the game would positively impact one's intellectual wellness (H3). In the path analysis, the path from playing the game to intellectual wellness is, indeed, statistically significant $(\beta=0.113, t=2.68 \mathrm{p}<.05)$, which supports hypothesis H3: Playing Pokémon Go influences one's intellectual wellness. Relatedly, in hypothesis $\mathrm{H} 8$ we stated that the player's intellectual wellness is related to her overall wellness. The path from the intellectual wellness to the overall wellness is not statistically significant in the path model (H8 not supported). Taken together, these findings suggest that while playing Pokémon Go has a positive effect on the player's overall intellectual wellness, intellectual wellness is a minor issue in our sample. We can conjecture that since cognitive problems accumulate with age, they have little effect on the relatively young population of Pokémon Go players.

The impact of playing Pokémon Go on spiritual wellness

Since playing Pokémon Go offers consistent opportunities for goal pursuit and rewards for attaining the goals, we believed that playing Pokémon Go would positively impact one's spiritual wellness (hypothesis H4). In the path analysis, the path from playing Pokémon Go to spiritual wellness is, indeed, statistically significant $(\beta=129, t=4.03 \mathrm{p}<.001)$, which supports the hypothesis. Relatedly, in H9 we stated that the player's spiritual wellness should be related to her overall wellness. However, in the analysis the path from the spiritual wellness to the overall wellness was not statistically significant and thus (H9 is not supported). It seems that playing Pokémon Go has positive impact on one's spiritual wellness yet the dimension itself does not impact the overall wellness in the population of the Pokémon Go players.

The impact of playing Pokémon Go on emotional wellness

Playing Pokémon Go, as playing games in general, involves a component of having fun, which led us to believe that playing Pokémon Go would positively impact one's emotional wellness (H5). The path from playing Pokémon Go to emotional wellness is statistically significant $(\beta=0.094, t=2.21, \mathrm{p}<.05)$, which supports the hypothesis. Relatedly, in H10 we stated that the player's emotional wellness should be related to her overall wellness. The path from the 
emotional wellness to the overall wellness was statistically significant $(\beta=0.431, t=6.62 \mathrm{p}<.000)$. This suggests that a change in emotional wellness directly affects overall wellness in the population of Pokémon Go players.

\section{Conclusion}

The aim of this paper was to find out if playing Pokémon Go positively affects its player's wellness. We identified five major dimensions of wellness, including physical, social, intellectual, spiritual, and emotional. Previous research suggests a positive relationship between playing Pokémon Go and physical activity. However, little published research can be found about what kind of influence Pokémon Go has on its players in the greater scheme of wellness. For example, Yang and Liu [45] studied the motives for playing Pokémon Go and have found both fun and friendship maintenance positively correlate with wellbeing, and relationship initiation is associated with both better and poorer wellbeing. We find a positive relationship between playing Pokémon Go and intellectual, spiritual and emotional dimension of wellness. We did not find, however, any significant relationship between playing Pokémon Go and dimensions of physical and social wellness. This is quite surprising considering that the game developers have invested considerable effort to design in the Pokémon Go game features that should encourage physical activity, social encounters and group playing. We can only assume that playing the game does not considerably increase the amount of physical activity and socializing at the population level. Rather, playing the game may substitute other kinds of physical activity and game playing may take place inside one's existing social circles. Despite Pokémon Go having a reputation of being a social game, its influence on the players' social wellness seems surprisingly weak. Lastly, we want to lift up the impact of playing Pokémon Go on one's emotional wellness. It seems that people enjoy playing the game and that emotional wellness is a meaningful dimension of wellness in the relatively young population of active Pokémon Go players. We all tend to have our ups and downs and if a game can improve its players' emotional wellbeing, it has certainly made a worthwhile contribution. Similar to other research our paper has some limitations, for instance our correlational data did not allow us to account for the causality between playing game and improved wellbeing. Longitudinal and experimental designs are needed to investigate the causality and directionality of the relationships. In addition, using distance played as a playing indicator also has some limitations, for example, for obese users, less distance travelled might still be a big difference in their behavior and positive impact on their wellbeing. Lastly, the findings of this research may not fully represent the entire population of the Pokémon Go players.

\section{References}

[1] Rideout, V. J., Foehr, U. G., and Roberts, D. F. (2010). GENERATION M² Media in the lives of 8- to18-year-olds. The Henry J. Kaiser Family Foundation. Retrieved August 26, 2017, from http://files.eric.ed.gov/fulltext/ED527859.pdf. [2] Swant, M. (2017). Pokemon Go Has Now Driven 500 Million Visits to Sponsored Locations. Emerging Tech. Retrieved August 26, 2017, from http://www.adweek.com/digital/pokemon-go-has-nowdriven-500-million-visits-to-sponsored-locations/. [3] Althoff, T., While, R. W., and Horvitz, E. (2016). Influence of Pokémon Go on Physical Activity: Study and Implications. Journal of Medical Internet Research, 18(12), e315.

[4] Corbin, C. B., and Pangrazi, R. P. (2001, December). Toward a Uniform Definition of Wellness: A Commentary. Research Digest, 3(15), 1-10.

[5] Corbin, D., Pangrazi, R., and Franks, B. (2000).

Definitions: Health, fitness and physical activity. President's Council on Physical Fitness and Sports Research Digest, 3(9), 1-9.

[6] Dunn, L. H. (1959). High-Level Wellness for Man and Society. Journal of the National Medical Association, 49(6), 786-792.

[7] Thoits, P. A. (1992). Identity Structures and Psychological Well-Being: Gender and Martial Status Comparisons. Social Psychology Quarterly, 55(3), 236-256. [8] Hettler, B. (1976). The Six Dimensions of Wellness Model. Retrieved from National Wellness Institute: http://www.nationalwellness.org/?page=AboutWellness [9] Hattie, J. A., Myers, J. E., and Sweeny, T. J. (2004). A Factor Structure of Wellness: Theory, Assessment, Analysis and Practice. Journal of Counseling \& Development, 82, 354-364.

[10] Pew Research Center. (2017). Mobile Fact Sheet. Retrieved August 26, 2017, from

http://www.pewinternet.org/fact-sheet/mobile/. [11] Haskell, W. L., Lee, I.-M., Pate, R. R., Powell, K. E., Blair, S. N., Franklin, B. A., . . . and Bauman, A. (2007). Physical Activity and Public Health: Updated Recommendation for Adults from the American College of Sports Medicine and the American Heart Association. Medicine \& Science in Sports \& Exercise, 39, 1423-1434. [12] Keyes. C, L. M. (1998). Social Well-Being. Social Psychology Quarterly, 61(2), 121-140.

[13] DeWall, C. N., and Bushman, B. J. (2011). Social Acceptance and Rejection: The sweet and the Bitter. Current Directions in Psychological Science, 20(4), 256-260.

[14] Michelon, P. (2006). What are Cognitive Abilities and Skills, and How to Boost them? Retrieved 11 01, 2016, from Sharpbrains: http://sharpbrains.com.

[15] Park, D. C., Gutchess, A. H., Meade, L. M., and StineMorrow, E. A. (2007). Improving Cognitive Function in 
Older Adults: Nontraditional Approaches. Journal of Gerontology: SERIES B, 62B(1), 45-52.

[16] Chandler, C. K., Holden, J. M., and Kolander, C. A. (1992). Counseling for Spiritual Wellness: Theory and Practice. Journal of Counseling \& Development, 71, 168175.

[17] Hinterkopf, E. (1994). Integrating Spiritual Experience in Counseling. Counseling \& Values, 38(3), 165-175.

[18] Jones, J. P., and Frazier, S. E. (1994). Assessment of Self-Esteem and Wellness in Health Promotion Professionals. Psychological reports, 75, 833-834.

[19] Abood, D., and Conway, T. (1992). Health Value and Self-Esteem as Predictors of Wellness Behavior. The Journal of Health Behavior, Education \& Promotion, 16(3), 20-26. [20] Time Magazine. (1999, November). The Ultimate Game Freak. Time Magazine. Retrieved August 26, 2017, from http://content.time.com/time/magazine/article/0,9171,204009 5,00.html.

[21] The Pokémon Company. (2017). Company History. Retrieved August 26, 2017, from The Pokémon Company: http://www.pokemon.co.jp/corporate/en/history/. [22] Hanke, J. (2016). The story behind "Pokémon Go's" impressive mapping. (A. Bogle, Interviewer) Mashable. Retrieved August 26, 2017, from http://mashable.com/2016/07/10/john-hanke-pokemongo/\#cIYgFvwKbkqH.

[23] Darrington, S. (2016). Pokémon Go. Children's Book and Media Review, 37(8).

[24] The Pokémon Wiki. (2017). Ash Ketchum. Retrieved August 26, 2017, from The Pokémon Wiki:

http://pokemon.wikia.com/wiki/Ash Ketchum.

[25] Pan, A. (2016). Pokemon Go Guide: How to Get Pokecoins. Retrieved August 26, 2017, from GAMERANT: https://gamerant.com/pokemon-go-pokecoins-guide/2/.

[26] Klepis, N. E., Nelson, W. C., Ott, W. R., Robinson, J. P., Tsang, A. M., Switzer, P., and Engelmann, W. (2001). The National Human Activity Pattern Survey (NHAPS) "A Resource for Assessing Exposure to Environmental Pollutants". Journal of exposure analysis and environmental epidemiology, 3, 231-252.

[27] Holick, M. F. (2004). Sunlight and vitamin D for bone health and prevention of autoimmune diseases, cancers, and cardiovascular diseases. American Society for Clinical Nutrition, 80(6), 1678-1688.

[28] Stothard, E. R., McHill, A. W., Depner, C. M., Birks, B. R., Moehlman, T. M., Ritchie, H. K., ... and Wright, K. P. (2017). Circadian entrainment to the natural light-dark cycle across seasons and the weekend. Current Biology, 27(4), 508-513.

[29] Pokemongo. (2017). Pokémon Go frontpage. Retrieved August 26, 2017, from Pokémon Go:

http://www.pokemongo.com/.

[30] Westgate, C. E. (1996). Spiritual Wellness and Depression. Journal of Counseling \& Development, 75, 2635.

[31] Moore, A. (2013). The Standford Encyclopedia of Philosophy "Hedonism". Metaphysics Research Lab, Standford University.

[32] Leary, M. R. (2016). Making Sense of Self-Esteem.

Current Directions in Psychological Science, 8(1), 32-35.
[33] Henseler, J., Ringle, C. M., and Sarstedt, M. (2015). A new criterion for assessing discriminant validity in variancebased structural equation modelling. Journal of the Academy of Marketing Science, 43(1), 115-135.

[34] Urbach, N., and Ahlemann, F. (2010). Structural Equation Modelling in Information Systems Research Using Partial Least Squares. Journal of Information Technology Theory and Application, 11(2), 5-40.

[35] Hair, J. F., Black, W. C., Babin, B. J., and Anderson, R. E. (2010). Multivariate Data Analysis (7 Ed.). Pearson.

[36] Rogelberg, S. G. (2016). The SAGE Encyclopedia of Industrial and Organizational Psychology (Vol. 2). Sage Publications.

[37] Foster, L. T., and Keller, C. P. (2007). The British Columbia Atlas of Wellness. Canadian Western Geographical Series 1st Edition, 1-250.

[38] Copeland, M. E. (2002). Wellness Recovery Action Plan. Occupational Therapy in Mental Health, 17, 127-150. [39] Wright, S. (1960). Path coefficients and path regressions: alternative or complementary concepts? Biometrics, 16(2), 189-202.

[40] Sonders, M. (2016). SurveyMonkey Intelligence "Pokémon GO demographics: The evolving player mix of a smash-hit game. Retrieved August 26, 2017, from

SurveyMonkey Intelligence:

https://medium.com/@sm app intel/pok\%C3\%A9mon-godemographics-the-evolving-player-mix-of-a-smash-hit-gameb9099d5527b7.

[41] Hooper, D., Coughlan, J., and Mullen, M. R. (2008). Structural Equation Modelling: Guidelines for Determing Model Fit. Electronic Journal of Business Research Methods, 6(1), 53-60.

[42] Koistinen, P. O., Elo, S., Ahlroth, M., Kokko, J., Suistio, S., Kujala, V., and Rissanen, T. (2013).

OLDWELLACTIVE- A self-rated wellness profile for the assessment of wellbeing and wellness activity in older people. European Geriatric Medicine, 4(2), 82-85.

[43] Foster, T. W., and Levitov, J. E. (2012). Wellness During Midlife and Older Adulthood: A Different Perception. Adultspan Journal, 11(2), 66-76.

[44] Kogan, L., Hellyer, P., Duncan, C., and SchoenfeldTacher, R. (2017). A pilot investigation of the physical and psychological benefits of playing Pokémon GO for dog owners. Computers in Human Behavior, 76(2017), 431-437. [45] Althoff, T., White, R. W., and Horvitz, E. (2016). Influence of Pokémon GO on physical activity: Study and implications. Journal of Medical Internet Research, 18(12): e315.

[46] Howe, K. B., Suharlim, C., Ueda, P., Howe, D., Kawachi, I., and Rimm, E. B. (2016). Gotta catch'em all! Pokémon GO and physical activity among young adults: Difference in differences study. BMJ, 355, 16270. https://doi.org/10.1136/bmj.i6270.

[47] Bonus, J. A., Peebles, A., Mares, M. L., and Sarmiento, I. G. (2017). Look on the bright side (of media effects): Pokémon Go as a catalyst for positive life experiences. Media Psychology, 1-25.

http://dx.doi.org/10.1080/15213269.2017.1305280. 